\title{
Antibacterial Effects of Guava (Psidium guajava L.) Extracts Against Food Borne Pathogens
}

\author{
Jasmin Ara Farhana ${ }^{1, ~ *, ~ M d . ~ F a r u k ~ H o s s a i n ~}{ }^{2}$, Aleya Mowlah ${ }^{2}$ \\ ${ }^{1}$ Department of Human Nutrition and Dietetics, Patuakhali Science and Technology University, Patuakhali, Bangladesh \\ ${ }^{2}$ Institute of Nutrition and Food Science, University of Dhaka, Dhaka, Bangladesh
}

Email address:

jasminarafarhana@gmail.com (J. A. Farhana)

${ }^{*}$ Corresponding author

\section{To cite this article:}

Jasmin Ara Farhana, Md. Faruk Hossain, Aleya Mowlah. Antibacterial Effects of Guava (Psidium guajava L.) Extracts Against Food Borne Pathogens. International Journal of Nutrition and Food Sciences. Vol. 6, No. 1, 2017, pp. 1-5. doi: 10.11648/j.ijnfs.20170601.11

Received: October 19, 2016; Accepted: November 19, 2016; Published: December 20, 2016

\begin{abstract}
Guava is commonly used as a medicine against gastroenteritis and child diarrhea by those who cannot afford or do not have access to antibiotics. The present study was conducted to clarify the possible effects of antimicrobial activities of guava extracts. Its antimicrobial activities was determined against five food-borne pathogens: Staphylococcus aureus (ATCC 25923), Escherichia coli (ATCC 25922), Bacillus cereus (BTCC 19), Shigella sonnei (BTCC) and Salmonella typhi (BTCC 197 ) using disc diffusion method at four different concentrations: $10 \%, 50 \%, 75 \%$ and $100 \%$. Its antibacterial activity was also determined at three different temperatures: $50^{\circ} \mathrm{C}, 75^{\circ} \mathrm{C}$ and $100^{\circ} \mathrm{C}$. The test organisms differed in their reaction to these different extracts, but as a whole inhibition of bacterial growth increased with the increased concentration. All the samples showed antibacterial activity after heat treatment at $50^{\circ} \mathrm{C}, 75^{\circ} \mathrm{C}$ and $100^{\circ} \mathrm{C}$ suggesting that the temperature does not affect the activity. Guava extracts showed higher antibacterial activity against gram positive bacteria compared to gram negative bacteria. None of the extracts $(10 \%)$ showed antibacterial activity against these pathogens. The results of the present study assume that guava extracts possess compounds containing antibacterial properties that can potentially be useful to control food borne pathogens especially diarrhea causing organisms.
\end{abstract}

Keywords: Antibacterial Effect, Food, Food Borne Pathogen, Test Organism, Media

\section{Introduction}

Psidium guajava L. (guava), a fruit plant belonging to the family Myrtaceae, is found all over the world. Guava leaves, roots, and fruits have been used for the prevention and treatment of diarrhea $[1,2]$. In several studies, guava showed significant antibacterial activity against common food borne diarrhea-causing bacteria such as Staphylococcus spp., Shigella spp., Salmonella spp., Bacillus spp., E. coli, Clostridium spp., and food spoilage bacteria such as Pseudomonas spp. [2-5]. Guava is also used medicinally in many parts of the world as an anti-inflammatory and antiseptic as well as in the treatment of diabetes, hypertension, pain, fever, respiratory disorders, gastroenteritis, diarrhea and dysentery [6].

Guava fruits also contain vitamin $\mathrm{C}$, iron, calcium and phosphorus. Guava plants also contain some secondary metabolites. Much of guava therapeutic activity was attributed to these flavonoids. The flavonoids had demonstrated antibacterial activity. Guava also had antioxidant properties which were attributed to the polyphenols found in the leaves.

The problem of microbial resistance is growing and the outlook for the use of antimicrobial drugs in the future is still uncertain. Therefore, actions must be taken to reduce this problem, for example, to control the use of antibiotic, develop research to better understand the genetic mechanisms of resistance, and to continue studies to develop new drugs, either synthetic or natural. The ultimate goal is to offer appropriate and efficient antimicrobial drugs to the patient. Development of microbial resistance to the available antibiotics has led scientists to introduce the antibacterial activity of medicinal plants $[7,8]$. The use of plant extracts and phytochemicals, both with known antimicrobial 
properties, can be of great significance in therapeutic treatments. In the last few years, a number of studies have been conducted in different countries to prove such efficiency [10-15]. Many plants have been used because of their antimicrobial traits, which are due to compounds synthesized in the secondary metabolism of the plant. These products are known by their active substances, for example, the phenolic compounds which are part of the essential oils [16], as well as in tannin [17]. The major antimicrobial components of plants and their essential oils are, for example, gallotannins in mango, comarins, essencial oils, flavonoids, triterpenes and ellagitannins in Guava, ellagic acid in grapes, cherries, pomegranate, strawberries, raspberries, blackberries, apples and some nuts, terpenes in citrus fruits, such as oranges, lemons, grapefruit and tangerines, and in cherries [18]. Guava juice is very popular in Cuba, Costa Rica, Egypt, Mexico, Colombia, Hawaii, Puerto Rico, Venezuela, Malaysia, Indonesia and South Africa. The fruit is also often prepared as a dessert, in fruit salads. In Asia, fresh guava slices are often dipped in preserved prune powder or salt. In India it is often sprinkled with red rock salt, which is very tart. Because of its high level of pectin, guavas are extensively used to make candies, preserves, jellies, jams, and marmalades (such as Brazilian goiabada and Colombian bocadillo), and also for juices and aguas frescas. "Red" guavas can be used as the base of salted products such as sauces, substituting for tomatoes, especially for those sensitive to the latter's acidity. In Asia, a drink is made from an infusion of guava fruits and leaves. The author has been working with guava extracts which have excellent activity against Staphylococcus aureus, Escherichia coli, Bacillus cereus, Shigella sonnei and Salmonella typhi. This study is to be undertaken to develop antibiotic substitute for the reduction of pathogens in foods or food items in Bangladesh. This can motivate farmers to grow guava for which they can earn money. This will create employment opportunities in the country.

\section{Materials and Method}

\subsection{Sample}

Guava was collected the New Market of Dhaka city (local species)

\subsection{Test Organisms}

A total of 5 species of frequently reported food borne pathogens were used as test organisms in this study. The name of organism, type culture and source of collection were listed in Table 1. The long-term stock cultures of the test organisms were maintained in $20 \%$ glycerol in cryogenic vials and were kept at $-70^{\circ} \mathrm{C}$. Working cultures were maintained on Nutrient Agar slants and were kept at $4^{\circ} \mathrm{C}$. The Nutrient Agar slants cultures were periodically transferred onto fresh Nutrient Agar slants.
Table 1. Test organisms used in this study.

\begin{tabular}{lll}
\hline Organisms & $\begin{array}{l}\text { No. of type } \\
\text { culture }\end{array}$ & Source \\
\hline Staphylococcus aureus & ATCC 25923 & Professor. Skerman, Australia \\
Escherichia coli & ATCC 25922 & INFS, DU \\
Salmonella typhi. & BTCC 197 & ICDDRB'B \\
Bacillus cereus & BTCC 19 & Professor. Skerman, Australia \\
Shigella sonnei & BTCC & INFS, DU \\
\hline
\end{tabular}

\subsection{Media}

Two types of media were used for the determination of antibacterial activity of the guava

\subsubsection{Nutrient Agar (NA)}

Nutrient agar was used as a basal medium. Nutrient agar is reliable generally for susceptibility testing. Dehydrated Nutrient agar was used.

\subsubsection{Nutrient Broth (NB)}

Nutrient broth was prepared for the inocula preparation. Nutrient broth contained all the components of the Nutrient Agar except the agar.

\subsection{Method}

\subsubsection{Preparation of Sample Extracts}

Fresh guava was purchased from the New Market of Dhaka city. The guava was peeled to obtain the edible portion. $250 \mathrm{~g}$ edible portion of the guava was chopped in a blender. Then this chopped material was filtered through Whatman filter paper to obtain the fresh extracts of the products. This fresh extracts was used after making their concentration $10 \%, 50 \%, 75 \%$ and $100 \%$.

\subsubsection{Preparation of Nutrient Agar}

Nutrient agar was prepared from a commercially available dehydrated base according to the manufacturer's instructions. Immediately after autoclaving, it was allowed to cool in a $45^{\circ} \mathrm{C}$ to $50^{\circ} \mathrm{C}$ water bath. The freshly prepared and cooled medium was poured into sterile glass flat-bottomed Petri plate on a level, horizontal surface to give a uniform depth of approximately $4 \mathrm{~mm}$. The agar medium was allowed to cool to room temperature and, the plate was used on the same day, or was stored in incubator $\left(37^{\circ} \mathrm{C}\right)$.

\subsubsection{Impregnation of Filter Paper Discs}

Discs (6 $\mathrm{mm}$ in diameter) made of Whitman filter paper no.1 (ADVANTEC; Toyo Roshi Kaisha, Ltd. Japan) were impregnated with $50 \mu \mathrm{l}$ of each $10 \%, 50 \%, 75 \%$ and $100 \%$ diluted extracts and were then dried at $40^{\circ} \mathrm{C}$ for overnight in hot air oven and were stored at $4^{\circ} \mathrm{C}$ until use. Negative control (with no extracts) was prepared.

\subsubsection{Preparation of Inocula}

One loopful of inoculum of each test organism from cryogenic vial was transferred into $9 \mathrm{ml}$ of sterile Nutrient Broth (NB) and grown at $37^{\circ} \mathrm{C}$ for 24 hours. One loopful of the NB culture was then streaked into the Nutrient Agar plate and grown at $37^{\circ} \mathrm{C}$ for 24 hours.

The inocula of the test organisms were prepared by 
transferring 3 to 4 colonies of the cultures on Nutrient Agar into $9 \mathrm{ml}$ of sterile NB and incubated in shaking water bath set at $37^{\circ} \mathrm{C}$ for 12 to 18 hours.

\subsubsection{Inoculation of Test Plates}

Within 15 minutes after adjusting the turbidity of the inoculums suspension, a sterile cotton swab was dipped into the adjusted suspension. The swab was rotated several times and pressed firmly on the inside wall of the tube above the fluid level. This removed excess inoculums from the swab. The dried surface of a Nutrient agar plate was inoculated by streaking with swab over the entire sterile agar surface. This procedure was repeated by streaking two more times, rotating the plate approximately $60^{\circ}$ each time to ensure an even distribution of inoculums.

\subsubsection{Application of Discs to Inoculated Agar Plates}

The guava extracts impregnated discs were dispensed onto the surface of the inoculated agar plate at appropriate spatial arrangement using an ethanol dipped and flamed forceps. Each disc was pressed down to ensure complete contact with the agar surface. The discs were placed so that they are no closer than $24 \mathrm{~mm}$ from centre to centre of the discs. For each plate 4 discs were placed. The plates were inverted and placed in an incubator at $37^{\circ} \mathrm{C}$ for 24 hours

\subsubsection{Evaluation of Plates}

Antibacterial activity was evaluated by measuring the zones of inhibition in $\mathrm{mm}$ (including the $6 \mathrm{~mm}$ disk) with calipers near the agar surface and the results were recorded. A reading of $6 \mathrm{~mm}$ means no zone of inhibition. The end point was taken as complete inhibition of growth as determined by the naked eye. Each sample was tested in triplicates and assay in this experiment was repeated thrice. Each sample was tested in $10 \%, 50 \%, 75 \%$ and $100 \%$ concentrations.

\subsubsection{Effect of Temperature on Antimicrobial Activity of Guava}

The effects of temperature on antimicrobial activity of guava extracts were determined by the defined methods [19].

\subsubsection{Determination of Antimicrobial Activity at Different Temperatures}

After the temperature treatment of each raw sample extracts at $50^{\circ} \mathrm{C}, 75^{\circ} \mathrm{C}$ and $100^{\circ} \mathrm{C}$, the antibacterial activity of these raw extracts was carried out against the test organisms. The antibacterial activity was assayed by the disc diffusion methods.

\subsubsection{Statistical Analysis}

The inhibition zones were calculated as means $\pm \mathrm{S}$. D. $(n=3$ or 4). The significance among different data was evaluated by analysis of variance (ANOVA) using Microsoft Excel program. Significant differences in the data were established by least significant difference at the $5 \%$ level of significance.

\section{Results and Discussion}

Table 2. The antibacterial activity of Guava extracts.

\begin{tabular}{lllll}
\hline \multirow{2}{*}{ Organisms } & \multicolumn{4}{l}{ Zone of inhibition $(\mathbf{m m})$} \\
\cline { 2 - 5 } & \multicolumn{2}{l}{ Concentration \% } & $\mathbf{1 0 \%}$ \\
\cline { 2 - 5 } & $\mathbf{1 0 0 \%}$ & $\mathbf{7 5 \%}$ & $\mathbf{5 0 \%}$ & - \\
\hline $\begin{array}{l}\text { Staphylococcus } \\
\text { aureus }\end{array}$ & $12.67 \pm 1.25$ & $10.5 \pm 0.41$ & $9.33 \pm 1.55$ & - \\
Salmonella typhi & $9.83 \pm 0.24$ & $8 \pm 0.82$ & - & - \\
Escherichia coli & $13.5 \pm 0.41$ & $12 \pm 0.41$ & $10.17 \pm 0.24$ & - \\
Bacillus cereus & $17 \pm 1.22$ & $13.33 \pm 0.9$ & $11 \pm 1.41$ & - \\
Shigella sonnei & $8.67 \pm 0.47$ & - & - & - \\
\hline
\end{tabular}

Zones of inhibition were measured as the diameter (in millimeters) and include the 6-mm-diameter disc. Data are mean \pm standard deviation.

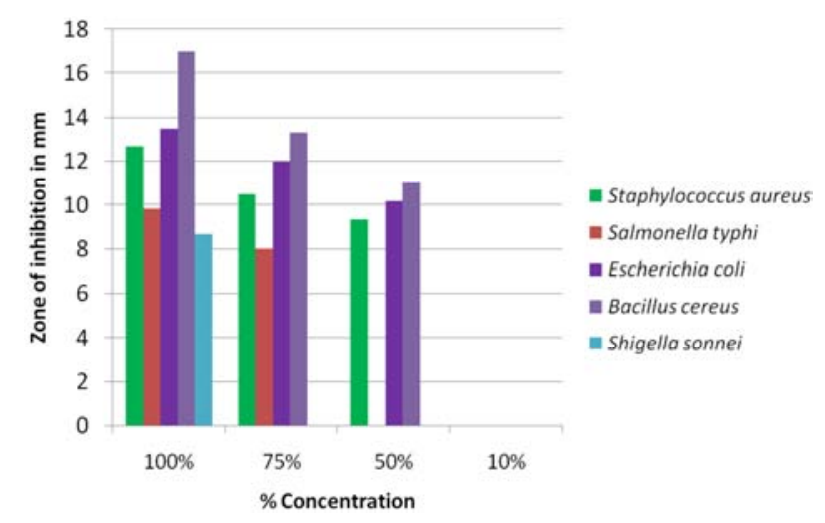

Figure 1. Antibacterial activity of guava extracts.

Table 3. Effect of temperature on antibacterial activity of Guava extracts.

\begin{tabular}{llll}
\hline \multirow{2}{*}{ Organisms } & \multicolumn{4}{l}{ Zone of inhibition $(\mathbf{m m})$} \\
\cline { 2 - 4 } & \multicolumn{4}{l}{ Temperature in ${ }^{\circ} \mathbf{C}$} \\
\cline { 2 - 4 } & $\mathbf{1 0 0}^{\circ} \mathbf{C}$ & $\mathbf{7 5}^{\circ} \mathbf{C}$ & $\mathbf{5 0}^{\circ} \mathbf{C}$ \\
\hline Staphylococcus aureus & 11.5 & $15.67 \pm 0.94$ & $14.33 \pm 0.62$ \\
Salmonella typhi & - & $8.33 \pm 0.62$ & $10.17 \pm 0.24$ \\
Escherichia coli & - & - & - \\
Bacillus cereus & $10.67 \pm 0.94$ & $9.67 \pm 1.03$ & $7 \pm 0.41$ \\
Shigella sonnei & - & 6.5 & $6.83 \pm 0.24$ \\
\hline
\end{tabular}

Zones of inhibition were measured as the diameter (in millimeters) and include the 6-mm-diameter disc. Data are mean \pm standard deviation.

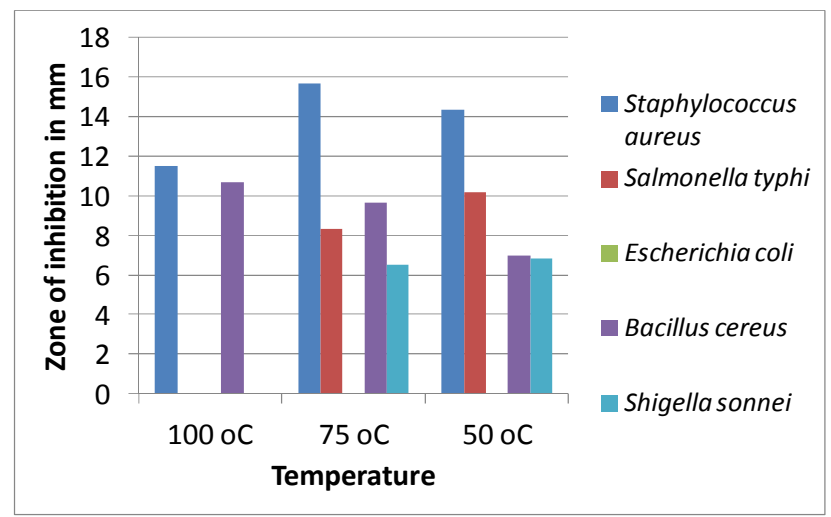

Figure 2. Effect of temperature on antibacterial activity of guava extracts 
With the view of searching local and common plants having antibacterial properties for application in preventing food-borne diseases, guava extracts were examined in this study. Their raw aqueous extractions were screened for their antibacterial activity against 5 common food-borne pathogens. All of them were positively screened against them.

Guava extracts have previously been demonstrated as broad spectrum antibacterial. Most recently Goncalves et al [20] reported antimicrobial effect of guava extracts. This is therefore, in pursuance of the efforts to search for drugs from plants and the verification of the scientific basis of some known practice in traditional medicine.

In this study, different concentrations of guava extracts were prepared instantly. Different concentrations were prepared such as $100 \%, 75 \%, 50 \%$ and $10 \%$ by addition of sterile distilled water to the raw extracts. The findings of guava extracts of different concentration correlated with the findings of Goncalves et al. [20] who applied guava extracts against food borne pathogen and spoilage bacteria. The guava extracts under this study consist of phenolic componenets, which render them effective against the test microorganisms. This was confirmed by Malaviya et al. [21]. And the observations in case of guava extracts matched with that of the finding of Hoque et al. [22] and showed that the antibacterial activity of guava and guava leaf extracts mostly attributed to the action of its principal phenolic components and both of these exhibit significant bactericidal activities when tested separately. However, subsequent studies provide evidence that phenolic compounds, particularly flavonoids, are responsible for antibacterial properties of guava [22]. These observations also correlated with Ismail et al. [23] who exhibited the antibacterial activity of guava against food borne pathogens.

In this study the antibacterial activity of guava extracts was determined against five bacteria by the disc diffusion method [24]. The blank discs (negative control) did not show any inhibiting activity for all the five bacteria studied. The results presented in Table 2 and 3 showed that the guava extracts under investigation exhibited marked antibacterial activity as evidenced by their zones of inhibition. This finding is reasonable; because, antibacterial activity of fruits depend on several factors, which include: a) different species, b) composition and concentration, c) microbial species and its occurrence level, d) processing conditions and storage [25-26]. These results were correlated with the findings of previous study of Malaviya et al. [21], who also applied raw extracts. In a similar study by Hoque et al [22], guava and neem were tested for antibacterial activity against Listeria monocytogenes (five strains), Staphylococcus aureus (four strains), E. coli 0157: H7 (six strains), Salmonella enteritidis (four strains), Vibrio parahaemolyticus, and Bacillus cereus, and five food spoilage bacteria: Pseudomonas aeroginosa, $P$. putida, Alcaligenes faecalis, and Aeromonas hydrophila (two strains). All juices were effective in inhibiting the growth of these species except E. coli 0157: H7 and Salmonella enteritidis.
The results of this work showed that the raw aqueous extract of guava extracts have antibacterial properties. For all extracts, the widest zones of inhibition in guava extracts were obtained with Bacillus cereus; the narrowest zones of inhibition were obtained with Shigella sonnei with normal temperature.

Guava extracts showed range of inhibition zones between 17-8.67 mm. similar types of results were shown by different scientists [27-30].

Temperature is one of the major factors which have influence on bioactive compound. The effect of temperature was also determined in this study. The guava extracts with heat were showed activity with little variation compared to non heated extracts. The results showed the diameters for the zone of inhibition were almost same (with little variation) up to $75^{\circ} \mathrm{C}$ and at $100^{\circ} \mathrm{C}$ it showed some decreased activity. This might be due to partial exhaustion of bioactive components at high temperature above $60^{\circ} \mathrm{C}$. Similar type of findings was reported by Hoque et al. In this study, generally the highest activity was found at $50^{\circ} \mathrm{C}$ which was similar to the report of Hoque et al. [22]. Effective antibacterial activity of these extracts at $50^{\circ} \mathrm{C}$ suggested that these compounds may be used as even in the high temperature.

Guava extracts inhibits both gram positive and gram negative bacteria. In this study, there was two gram positive and three gram negative bacteria. Staphylococcus aureus \& Bacillus cereus are gram positive bacteria and E. coli, Shigella sonnei \& Salmonella typhi are gram negative bacteria. Bacillus cereus (a gram positive bacterium) was showed maximum zones of inhibition in guava extracts. If this study was done with several gram positive bacteria, there will be possibility of finding a variation between gram positive and gram negative bacteria which was found by Hoque et al. [22]. It is noted worthy that the antibacterial activity of guava leaf extracts were dependent on the concentration of the extracts [31].

\section{Conclusion}

As the rapid emergence of drug-resistant organisms necessitates the continuous search of new antibacterial substances, natural products may act as alternative for antibiotics and chemotherapeutic agents in certain circumstances. The results showed that the extract of $P$. guajava were able to inhibit the bacteria used in this study with different degree of inhibition. The information obtained may provide validation for its reported medicinal uses. In this way, we can establish safeguard against food borne pathogens especially diarrhea causing pathogens and develop a healthy nation.

\section{References}

[1] Lutterodt, G. D. Inhibition of gastrointestinal release of acetylcholine by quercetin as a possible mode of action of Psidium guajava leaf extracts in the treatment of acute diarrhoeal diseases. J Ethnopharmacology. 25:235-247, 1989. 
[2] Alnieida, C. C.; Karnikowski, M. G.; Flieto, R. and Baldisserotto, B. - Analysis of antidiarrhoic effect of plantsused in popular medicine. Rev. Saude Publica. 29: 428-433, 1995.

[3] Hidetoshi, A. and Danrio, G. - Isolation of antimi-crobial compounds from guava (Psidium guajava L.) and their structural elucidation. Biosci. Biotechnol. Biochem. 66: 17271730,2002

[4] Abdeirahirn, S. I.; Almadboul, A. Z.; Omer, M. E. A. and Elegami, A. - Antimicrobial activity of Psidium guajava L. Fitoterapia. 73:713-715, 2002.

[5] Jaiarj, P.; Khoohaswan, P; Wongkrajng, Y; Peungricha, P.; Suriyawong, P; Sumalsaraya, M. L. and Ruangsom-boon, M. L. - Anticough and antimicrobial activities of Psidiuni guajava Linn. leaf extract. J. Ethnopharmacol. 67: 203-212, 1999.

[6] Gutiérrez, R. M. P; Mitchell, S and Solis, R. V. - Psidium guajava: A review of its traditional uses, phytochemistry and pharmacology. J Ethnopharmacol. 117: 1-27, 2008.

[7] Cown, N. M. - Plant product as antimicrobial agents. Cln. Microbiol Rev. 12: 564, 1999.

[8] Nostro, A; Germano, M. P. D; Angelo, V; Marino, A and Cannatell, M. A. - Extraction method and bioautography for evaluation of medical plant antimicrobial activity. Lett. Appl. Microbiol. 30: 379, 2000.

[9] Almagboul, A. Z.; Bashir, A. K.; Farouk, A.; Salih A. K. M. Antimicrobial activity of certain Sudanese plants used in folkloric medicine. Screening for antibacterial activity. Fitoterapia 56, 331-337, 1985.

[10] Artizzu, N.; Bonsignore, L.; Cottiglia, F.; Loy, G. Studies of the diuretic and antimicrobial activity of Cynodon dactylon essencial oil. Fitoterapia 66, 174-175, 1995.

[11] Ikram, M.; Inamul, H. Screening of medicinal plants for antimicrobial activities. Fitoterapia 55, 62-64, 1984.

[12] Izzo, A. A.; Di Carlo, G.; Biscardi, D.; Fusco, R.; Mascolo, N.; Borreli, F.; Capasso, F.; Fasulo, M. P.; Autore, G. Biological screening of Italian medicinal plants for antibacterial activity. Phytother. Res. 9, 281-286, 1995.

[13] Kubo, L.; Muroi, H.; Himejima, M. Structure-antibacterial activity relationships of anacardic acids. J. Agri. Food Chem. 41, 1016-1019, 1993.

[14] Shapoval, E. E. S.; Silveira, S. M.; Miranda, M. L.; Alice, C. B.; Henriques, A. T. Evaluation of some pharmacological activities of Eugenia uniflora. J. Ethnopharmacol. 44, 136$142,1994$.

[15] Sousa, M.; Pinheiro, C.; Matos, M. E. O.; Matos, F. J.; Lacerda, M. I.; Craveiro, A. A. Constituintes Químicos de Plantas Medicinais Brasileiras. Universidade Federal do Ceará, Fortaleza, p. 385-388, 1991.

[16] Jansen, A. M.; Cheffer, J. J. C.; Svendsen, A. B. Antimicrobial activity of essencial oils: a 1976-1986 literature review. Aspects of test methods. Planta Med. 40: 395-398, 1987.
[17] Saxena, G.; McCutcheon, A. R.; Farmer, S.; Towers, G. H. N.; Hancock, R. E. W. Antimicrobial constituents of Rhus glabra. J. Ethnopharmacol. 42: 95-99, 1994.

[18] http://www.naturalbird.com/mcwatters/medicinal.htm

[19] Fu, X.; Deng, S.; Su, G.; Zeng, Q. and Shi, S. - Isolating highquality RNA from mangroves without liquid nitrogen. Plant Molecular Biology Reporter. 22 (2): 197a-198e, 2004.

[20] Gonçalves, F. A.; Andrade Neto, M.; Bezerra, J. N. S.; Macrae, A.; Sousa, O. V.; Fonteles-Filho, A. A. \& Vieira, R. H. S. F. - Antibacterial activity of guava, Psidium guajava Linnaeus, leaf extracts on diarrhea-causing enteric bacteria isolated from Seabob shrimp. Xiphopenaeus kroyeri (Heller). Rev. Inst. Med. trop. S. Paulo, 50 (1): 11-15, 2008.

[21] Malaviya, A and Mishra, N. - Antimicrobial activity of tropical fruits. Biological Forum - An International Journal, 3(1): 1-4: 2011

[22] Hoque, M. M.; Bari, M. L.; Inatsu, Y; Vijay, K; Juneja and Kawamoto, S. - Antibacterial Activity of Guava (Psidium guajava L.) and Neem (Azadirachta idica A. Juss.) extracts Against Foodborne Pathogens and Spoilage Bacteria. National Food Research Institute, Japan. 4 (4):481-488, 2007.

[23] Ismail, M; Minhas, P. S.; Khanum, F; Sahana, V. M. and Sowmya, C. - Antibacterial Activity of Leaves Extract of Guava (Psidium Guajava). International Journal of Research in Pharmaceutical and Biomedical Sciences. 3 (1): 1, 2012.

[24] Bauer, L; Kohlich, A; Hirschwehr, R; Siemann, U; Ebner, H; Scheiner, O; Kraft, D; Ebner, C. Food allergy to honey: pollen or bee products? Characterization of allergenic proteins in honey by means of immunoblotting. J Allergy Clin Immunol; 97 (1 Pt 1): 65-73, 1996

[25] Shelef, L. A. - Antimicrobial effects of spices. J Food Saf. 6: 29-44, 1983.

[26] Farag, R. S.; DAW, Z. Y.; Hewedi, F. M. and El-Baroty, G. S. A. - Antimicrobial activity of some Egyptian spice essential oils. J. Food Prot. 52: 665-667, 1989.

[27] Gnan, S. O. and Demello, M. T. - Inhibition of Staphylococcus aureus by aqueous Psidium guajava leaves extracts. J Ethnopharmacol. 68:103-108, 1999.

[28] Tona, L. - Biological screening of traditional preparations from some medicinal plants used as antidiarrhoeal in Kinshasa, Congo. Phytomedicine. 6: 59-66, 1999.

[29] Oliver-Bever, B. - Medicinal Plants in Tropical WestAfrica. Cambridge University Press, Cambridge, United Kingdom, 1986.

[30] Sanches, N.R.; Garcia, D. A.; Schiavini, M. S.; Naka-mura, C. V. and Filho, B. P. D. - An evaluation of anti-bacterial activities of Psidiuni gitajava. Brazilian Arch.Biol. Technol. 48:429-436, 2005.

[31] Ekwenye, U. N; Elegalam, N. N. - Antibacterial activity of Ginger (Zingiber officinale Roscoe) and garlic (Allium sativum L.) extracts on Escherichia coli and Salmonella typhi. Int J Mole Med Adv Sci 1 (4): 411-416, 2005. 